\title{
An Eye on Animacy and Intention
}

\author{
Dorothea U. Martin *, Conrad Perry and Jordy H. Kaufman \\ Swinburne Babylab, Brain \& Psychological Sciences Research Centre, Swinburne University of Technology, Hawthorn, VIC, \\ Australia
}

Keywords: eye-gaze, intention, animacy, infancy, social cognition

\section{A commentary on}

The case for social evaluation in preverbal infants: gazing toward one's goal drives infants' preferences for Helpers over Hinderers in the hill paradigm

by Hamlin, J. K. (2015). Front. Psychol. 5:1563. doi: 10.3389/fpsyg.2014.01563

Hamlin (2015) argued that the human capacity for social evaluation begins to emerge just a few months after birth. This claim derives from studies using unfulfilled goal scenarios, with infants as young as 3 months of age (see Hamlin, 2013). In a typical "manual choice" experiment, infants are habituated to multiple helping and hindering events. For example, a protagonist may first fail to achieve a goal such as climbing a hill. Then, another character pushes the protagonist either up the hill (the "Helper") or back down the hill (the "Hinderer"). Following habituation, infants are presented with the Helper and Hinderer. By 4.5 months of age, infants more often choose to reach for the Helper than the Hinderer. These results are interpreted as evidence for an early developing sense of morality (Hamlin, 2013, 2014; c.f. Cowell and Decety, 2015; Salvadori et al., 2015; Scola et al., 2015).

One potential issue with Hamlin et al.'s (2007) study, proposed by Scarf et al. (2012), is that the Helper events were confounded with an act of bouncing when the protagonist reached the hilltop. The current paper, however, showed that this was not the case, and that the direction of the protagonist's eye-gaze was the important factor. In this case, children chose the Helper over the Hinderer more often when the protagonist gazed at the hilltop. Hamlin argued that eye-gaze shows intent and that infants' understanding of intent allows them to correctly represent the behavior of the character as helping or hindering.

Regardless of whether eye-gaze served as a cue to intention, it is not surprising that gaze could have profound effects on infants' preferences. Eye contact and following others' gaze is a crucial part of our daily interactions. This sensitivity to eyes appears to be highly adaptive (Baron-Cohen, 1995; Langten et al., 2000). Even at birth when infants have poor visual acuity and ocular control, they have a preference for open over closed eyes (Batki et al., 2000) and direct over averted gaze (Farroni et al., 2002, 2006). At 6 months of age, an important milestone occurs as infants begin to follow others' eye gaze to targets inside their current field of view (D'Entremont et al., 1997; Gredebäck et al., 2008). The sensitivity to eye-gaze is assumed to have its roots in the evolution of the morphology of the human eye-which has an unusually high contrast between iris, sclera, and surrounding skin, enabling the detection of gaze direction from a great distance (Kobayashi and Kohshima, 1997, 2001; Tomasello et al., 2007).

Although, the eye-gaze is clearly important in the task of Hamlin, it is not entirely clear why. One possibility is that eye-gaze helps the understanding of intentions. Such an explanation has been proposed by Baron-Cohen $(1994,1995)$ who suggested that humans have an eye-direction detector that detects eye-like stimuli and computes gaze direction. This mechanism in conjunction with an Intentionality Detector and Shared Attention Mechanism trigger the development of the Theory-of-Mind-Mechanism (ToMM), which allows mental states, such as people's intentions, to be inferred. The actual age at which intentions can be understood, however, is debated with both 
Carpenter et al. (1998) and Tomasello et al. (1993, 2005) suggesting that such a skill does not emerge until the age of one, which is older than the children in Hamlin's (2015) study.

An alternative possibility is that infants prefer an event where someone "alive" is helped. In this case, infants may be responding to consistent animate action, regardless of any understanding of intentions (Tomasello et al., 2005). In particular, gaze may have been a cue for animacy in Hamlin's (2015) study when the climber's gaze was fixed on the hilltop (see Looser and Wheatley, 2010; Opfer and Gelman, 2010). Thus, infants may have preferred the Helper over the Hinderer in the "animate" condition, as only the Helper facilitated movements that were consistent with the previous event of ascending the first incline. If this is correct, then one would not need to assume infants of 6-11 months must understand the intentions of the puppet to do the task.

\section{REFERENCES}

Baron-Cohen, S. (1994). How to build a baby that can read minds: cognitive mechanisms in mindreading. Curr. Psychol. Cogn. 13, 513-552.

Baron-Cohen, S. (1995). Mindblindness an Essay on Autism and Theory of Mind. Cambridge, MA: MIT Press.

Batki, A., Baron-Cohen, S., Wheelwright, S., Connellan, J., and Ahluwalia, J. (2000). Is there an innate gaze module? Evidence from human neonates. Infant Behav. Dev. 23, 223-229. doi: 10.1016/S0163-6383(01)00037-6

Carpenter, M., Nagell, K., and Tomasello, M. (1998). Social cognition, joint attention, and communicative competence from 9-15 months of age. Monogr. Soc. Res. Child Dev. 63, i-vi, 1-143.

Cowell, J. M., and Decety, J. (2015). Precursors to morality in development as a complex interplay between neural, socioenvironmental, and behavioral facets. Proc. Natl. Acad. Sci. U.S.A. 112, 12657-12662. doi: 10.1073/pnas.1508832112

D'Entremont, B., Hains, S. M. J., and Muir, D. W. (1997). A demonstration of gaze following in 3- to 6-month-olds. Infant Behav. Dev. 20, 569-572. doi: 10.1016/S0163-6383(97)90048-5

Farroni, T., Csibra, G., Simion, F., and Johnson, M. H. (2002). Eye contact detection in humans from birth. Proc. Natl. Acad. Sci. U.S.A. 99, 9602-9605. doi: 10.1073/pnas.152159999

Farroni, T., Menon, E., and Johnson, M. H. (2006). Factors influencing newborns' preference for faces with eye contact. J. Exp. Child Psychol. 95, 298-308. doi: 10.1016/j.jecp.2006.08.001

Gredebäck, G., Theuring, C., Hauf, P., and Kenward, B. (2008). The microstructure of infants' gaze as they view adult shifts in overt attention. Infancy 13, 533-543. doi: 10.1080/15250000802329529

Hamlin, J. K. (2013). Moral judgment and action in preverbal infants and toddlers: evidence for an innate moral core. Curr. Dir. Psychol. Sci. 22, 186-193. doi: $10.1177 / 0963721412470687$

Hamlin, J. K. (2014). Context-dependent social evaluation in 4.5-monthold human infants: the role of domain-general versus domain-specific processes in the development of social evaluation. Front. Psychol. 5:614. doi: 10.3389/fpsyg.2014.00614

Hamlin, J. K. (2015). The case for social evaluation in preverbal infants: gazing toward one's goal drives infants' preferences for Helpers over Hinderers in the hill paradigm. Front. Psychol. 5:1563. doi: 10.3389/fpsyg.2014.01563

Hamlin, J. K., Wynn, K., and Bloom, P. (2007). Social evaluation by preverbal infants. Nature 450, 557-559. doi: 10.1038/nature06288

Kobayashi, H., and Kohshima, S. (2001). Unique morphology of the human eye and its adaptive meaning: comparative studies on external morphology of the primate eye. J. Hum. Evol. 40, 419-435. doi: 10.1006/jhev.2001.0468
Whether infants' preference for Helpers is based on an innate morality remains an open question. Nevertheless, Hamlin's (2015) experiments provided novel insights showing the importance of eye gaze for infants' choices. Because one has to understand the other's intention in order to act prosocially, future research addressing the question of whether young infants are truly able to infer from the Protagonist's gaze to its goals or if infants' choices are solely based on their predictions of future animate action would be of interest.

\section{AUTHOR CONTRIBUTIONS}

All authors listed, have made substantial, direct and intellectual contribution to the work, and approved it for publication.

Kobayashi, H., and Kohshima, S. (1997). Unique morphology of the human eye. Nature 387, 767-787.

Langten, S. R. H., Watt, R. J., and Bruce, V. (2000). Do the eyes have it? Cues to the direction of social attention. Trends Cogn. Sci. 4, 50-59. doi: 10.1016/S13646613(99)01436-9

Looser, C. E., and Wheatley, T. (2010). The tipping point of animacy: how, when, and where we perceive life in a face. Psychol. Sci. 21, 1854-1862. doi: 10.1177/0956797610388044

Opfer, J. E., and Gelman, S. A. (2010). "Development of the animate inanimate distinction," in The Wiley-Blackwell Handbook of Childhood Cognitive Development, ed U. Goswami (Malden, MA: Wiley-Blackwell), 213-238.

Salvadori, E., Blazsekova, T., Volein, A., Karap, Z., Tatone, D., Mascaro, O., et al. (2015). Probing the strength of infants' preference for Helpers over Hinderers: two replication attempts of Hamlin and Wynn (2011). PLoS ONE 10:e0140570. doi: 10.1371/journal.pone.0140570

Scarf, D., Imuta, K., Colombo, M., and Hayne, H. (2012). Social evaluation or simple association? Simple associations may explain moral reasoning in infants. PLoS ONE 7:e42698. doi: 10.1371/journal.pone.0042698

Scola, C., Holvoet, C., Arciszewski, T., and Picard, D. (2015). Further evidence for infants' preference for prosocial over antisocial behaviors. Infancy 20, 684-692. doi: 10.1111/infa.12095

Tomasello, M., Carpenter, M., Call, J., Behne, T., and Moll, H. (2005). Understanding and sharing intentions: the origins of cultural cognition. Behav. Brain Sci. 28, 675-691. doi: 10.1017/S0140525X050 00129

Tomasello, M., Hare, B., Lehmann, H., and Call, J. (2007). Reliance on head versus eyes in the gaze following of great apes and human infants: the cooperative eye hypothesis. J. Hum. Evol. 52, 314-320. doi: 10.1016/j.jhevol.2006.10.001

Tomasello, M., Kruger, A. C., and Ratner, H. H. (1993). Cultural learning. Behav. Brain Sci. 16, 495-511.

Conflict of Interest Statement: The authors declare that the research was conducted in the absence of any commercial or financial relationships that could be construed as a potential conflict of interest.

Copyright (c) 2016 Martin, Perry and Kaufman. This is an open-access article distributed under the terms of the Creative Commons Attribution License (CC BY). The use, distribution or reproduction in other forums is permitted, provided the original author(s) or licensor are credited and that the original publication in this journal is cited, in accordance with accepted academic practice. No use, distribution or reproduction is permitted which does not comply with these terms. 